\title{
Psicologia do Trânsito: Conquistas Históricas, ADI 3481 e Perspectivas para a Área
}

\author{
Fabián J. M. Rueda ${ }^{1}$ \\ ${ }^{1}$ Centro Universitário de Brasília, DF, Brasil
}

\author{
Juliana de Barros Guimarães ${ }^{2}$ \\ ${ }^{2}$ Departamento Estadual de Trânsito de Pernambuco, \\ PE, Brasil
}

Resumo: O presente artigo visa apresentar, discutir e refletir a Psicologia do Trânsito sob o olhar de alguns marcos históricos. O primeiro período compreende desde o início da área no Brasil até a promulgação do Código de Trânsito Brasileiro de 1997; em um segundo momento são apresentados os avanços da área assim como sua consolidação e contribuição para um momento bastante promissor da Psicologia do Trânsito; tais avanços são discutidos em um terceiro período do artigo, que compreende de 2018 a 2021. Na sequência, são discutidos aspectos que têm impactado diretamente o trabalho dos profissionais da área da Psicologia do Trânsito como a pandemia do SARS-CoV-2 (Covid-19), a Ação Direta de Inconstitucionalidade 3481 no Supremo Tribunal Federal e o Projeto de Lei no 3267/ 19 (transformado na Lei Ordinária $\mathrm{n}^{\circ}$ 14.071/2020) que alterou o Código de Trânsito Brasileiro desde que passou a vigorar em $12 \mathrm{de}$ abril de 2021. São propostas reflexões sobre esses novos desafios e são discutidas alternativas para o trabalho na área, visando uma adequação às novas demandas e realidade. Espera-se oferecer ao leitor a possibilidade de refletir novos caminhos para a área que visem um fazer ético, de qualidade e cujo objetivo principal seja preservar vidas.

Palavras-chave: Psicologia do Trânsito, Perícia psicológica, Testes psicológicos, Trânsito.

\section{Traffic Psychology: Historical Achievements, ADI 3481, and Prospects for the Area}

\begin{abstract}
This article aims to present, discuss, and reflect upon Traffic Psychology from the perspective of some historical milestones in three different periods. The first period refers to the origins of the field in Brazil until the promulgation of the 1997 Brazilian Traffic Code. Then, it approaches the advances within the field, as well as its consolidation and contributions - which will be discussed in-depth in the third period, including the years from 2018 to 2021. The article also discusses aspects that have impacted the professional practice of Traffic psychologists, namely the COVID-19 (SARS-CoV-2) pandemic, the 3481 Direct Action of Unconstitutionality of the Supreme Court, and the 3267/ 19 Bill (Ordinary Law 14071/2020), transformed into the new Brazilian Traffic Code, published in 2020. This review reflects upon these new challenges, proposing alternatives for the field to adapt to the new demands and reality. With that, it seeks to stimulate reflections regarding possibilities for the field of Traffic Psychology, always grounded on an ethical and quality professional practice with the primary purpose of preserving lives.
\end{abstract}

Keywords: Traffic Psychology, Psychological forensics, Psychological tests, Traffic. 


\title{
Psicología del Tránsito: Conquistas Históricas, la ADI 3481 y las Perspectivas para el Área
}

\begin{abstract}
Resumen: Este artículo tiene como objetivo presentar, discutir y reflexionar sobre la Psicología del Tránsito desde algunos marcos históricos. Los períodos abarcan desde el comienzo del área en Brasil hasta el momento de la publicación del Código de Tránsito Brasileño de 1997, después se presentan los avances del área y su consolidación, que contribuyeron para un momento bastante prometedor de la Psicología del Tránsito, el cual se discute en el tercer período que abarca de 2018 a 2021. En seguida, se discuten aspectos que pueden impactar e impactaron directamente el trabajo de los profesionales de la Psicología del Tránsito, como la pandemia del SARS-CoV-2 (Covid-19), la Acción Directa de Inconstitucionalidad del Supremo Tribunal Federal y el Proyecto de Ley 3267/19 (transformado en la Ley 14.071/2020) que alteró el Código de Tránsito Brasileño desde su vigencia el 12 de abril de 2021. Se proponen reflexiones sobre esos nuevos desafíos y se discuten alternativas para el trabajo en el área, con el objetivo de adecuarse a las nuevas demandas y nueva realidad. Se espera ofrecer al lector la posibilidad de reflexionar sobre nuevos caminos para el área, siempre pensando en un trabajo ético, de calidad y con el principal objetivo de preservar vidas.
\end{abstract}

Palabras clave: Psicología del Tránsito, Pericia Psicológica, Pruebas psicológicas, Tránsito.

\section{Dos primeiros passos ao Código de Trânsito Brasileiro de 1997}

A história da psicologia do trânsito no Brasil tem sido bastante descrita (para um aprofundamento maior, ver Rueda, 2011; Silva, 2012). No entanto, alguns aspectos ainda são importantes de serem destacados, principalmente aqueles que mostram e reforçam que a Psicologia do Trânsito surgiu extremamente relacionada à avaliação psicológica, ou mais especificamente, à utilização de testes psicológicos.

Se considerarmos o século XX para a Psicologia do Trânsito, pode-se afirmar que a área passou por momentos de ganhos, perdas, consolidação, conquistas, ou seja, de "altos" e "baixos". A esse respeito, desde a primeira legislação nacional de trânsito, o Decreto no 8.324, de 27 de outubro de 1910, que aprovou o regulamento para o serviço subvencionado de transportes por automóveis (Departamento Nacional de Trânsito [Denatran], 2010), muitas outras normativas oficiais foram publicadas, várias delas capazes de impactar diretamente a prática psicológica.

Destaque deve ser dado ao Decreto Lei no 2.994 de 28 de janeiro de 1941, que estabeleceu o primeiro Código Nacional de Trânsito, e que já determinava a exigência de exames médico e psicológico com o objetivo de estabelecer o "perfil psicofisiológico pro- fissional mínimo, compatível com o exercício da atividade", como forma de implementar políticas públicas protetivas e preventivas. Assim, a licença para conduzir passa a ser considerada uma concessão do Estado para os que comprovarem a capacidade de condução segura para as diferentes modalidades de atividade (amadora, profissional ou de transporte coletivo). Pouco tempo depois, em 25 de setembro de 1941, tal decreto foi alterado pela publicação do Decreto Lei no 3.651, que criou o Conselho Nacional de Trânsito (Contran) e os Conselhos Regionais de Trânsito (CRT) nas capitais dos estados. Um dos aspectos mais importantes das alterações tem a ver com o que Silva (2012) muito bem refere como sendo o primeiro veto à avaliação psicológica no processo de habilitação. $\mathrm{O}$ autor destaca que o Art. 108 estabelece que apenas o condutor culpado de acidente grave na via pública deveria passar por novo exame de visão e exame psicofisiológico. Tem-se aqui o primeiro momento em que aspectos psicológicos não seriam avaliados de forma preventiva. No entanto, a área ainda estava ensaiando uma forma de responder às demandas que se apresentavam no que diz respeito ao complexo sistema de trânsito. Ademais, pode-se perceber que, mesmo ainda sem uma diretriz muito nítida sobre o fazer profissional nesse contexto, sempre que o "perfil 
psicofisiológico' ou sua "avaliação" eram mencionados, o que estava em pano de fundo era a utilização de testes psicológicos que, à época, eram estrangeiros ou apenas traduzidos para o português.

Um marco legal muito importante, e talvez o ponto de partida para um fazer próximo do atual, foi a publicação do Decreto Lei no 9545 , de 5 de agosto de 1946, que determinava explicitamente que, para a habilitação e exercício da atividade de condutor de veículos automotores, era necessário que fosse organizado um "conjunto de testes para o exame psíquico", indicando a necessidade de que fossem "estabelecidas as médias normais do perfil psicofisiológico do condutor do veículo". Novamente, e desta vez de forma ainda mais nítida, há um papel e importância muito grande atribuídos aos testes.

Essa importância fica ainda mais evidente na década de 1940, se pensarmos que em 1947 foi criado o Instituto de Seleção e Orientação Profissional (ISOP), cujo principal objetivo era realizar atividade preventiva direcionada aos profissionais da condução com base na avaliação de características de personalidade e aptidão, utilizando, para isso, testes psicológicos. Aliado a isso, no mesmo período ocorreu a publicação dos Arquivos Brasileiros de Psicotécnica, revista que contribuiu bastante para o implemento e desenvolvimento dos "exames psicotécnicos” na avaliação dos condutores.

A partir de então, as décadas seguintes consolidaram a prática profissional da psicologia do trânsito como extremamente relacionada à utilização de testes. Exemplo disso foi o Departamento Estadual de Trânsito do Rio de Janeiro que, em 1951, contratou profissionais para "estudar o comportamento dos condutores com o objetivo de diminuir os acidentes de trânsito por meio da aplicação de testes psicológicos" (Rueda, 2011). Por sua vez, em 1953 o Contran tornou obrigatório o "exame psicotécnico" para todos os candidatos à profissão de motorista. Pode-se dizer que na década de 1950 o debate girou em torno da discussão de critérios, capacidades e condições mínimas para avaliação dos condutores por tipo de habilitação (profissional ou não) e por categoria de veículos, além da possibilidade de redução de prazos de validade do documento de habilitação e das verificações regulares. A esse respeito, Vieira, Pereira e Carvalho (1953) publicaram um trabalho nos Arquivos Brasileiros de Psicotécnica destacando que os construtos psicológicos mensurados na avaliação realizada no contexto do trânsito eram a personalidade e a atenção, enfatizando que a definição das condições mínimas necessárias para o ato de dirigir ainda não estavam estabelecidas.

A década de 1960 auxiliou na consolidação da área a partir da regulamentação da profissão, por meio da Lei $\mathrm{n}^{\circ}$ 4.119, de 27 de agosto de 1962, que definiu como função privativa do psicólogo a utilização de métodos e técnicas psicológicas com o objetivo de diagnóstico psicológico, de orientação e seleção profissional, de orientação psicopedagógica e de solução de problemas de ajustamento. Portanto, desde antes do próprio reconhecimento da profissão, a psicologia do trânsito já era uma das primeiras áreas de atuação profissional (Rueda, 2011).

As mudanças na década de 1960 também ocorreram nas regulamentações de trânsito, uma vez que após 25 anos de vigência foi promulgado um novo Código Nacional de Trânsito, pela Lei no 5.108 de 21 de setembro de 1966. Dentre as principais mudanças instituídas, estava a criação dos departamentos estaduais de trânsito, a obrigatoriedade de dispor, dentre outros, de serviços médico e psicotécnico e a determinação da padronização dos exames em todo o país. Pode-se afirmar que essa normativa trouxe o reconhecimento da importância dos fatores psicológicos para a segurança viária, e os psicólogos passaram então, oficialmente, a realizar os exames psicotécnicos para fins de obtenção da Carteira Nacional de Habilitação (CNH).

A criação do Conselho Federal de Psicologia (CFP) e dos Conselhos Regionais de Psicologia (CRP), pela Lei no 5.766 , de 20 de dezembro de 1971, auxiliou o desenvolvimento da psicologia do trânsito nas questões éticas, técnicas e legais, além de ser um meio de representatividade no diálogo com o poder público. Nas décadas seguintes, vê-se o surgimento efetivo de uma psicologia do trânsito e da segurança viária no país com a criação de vários núcleos de pesquisas, de cursos de pós-graduação e de atualização dos profissionais nas diversas áreas da segurança no trânsito e a realização de estudos e de publicações científicas, de modo que a psicologia passa a dialogar, efetivamente, com o sistema nacional de trânsito.

Nos anos seguintes, até a publicação do Código de Trânsito Brasileiro (CTB) de 1997, a área de psicologia do trânsito realizou os primeiros congressos nacionais da área, em 1982, 1983, 1985 e 1987, assim como pode se expandir para todos os estados do país. Sem dúvida, o foco de atuação da e do profissional da 
área estava centrado na avaliação de certas características para determinar se uma pessoa poderia ou não dirigir um veículo automotivo. No entanto, ainda se carecia de normativas específicas que definissem quais eram tais características. Todavia, não existia dúvida que o trabalho tinha como função principal a avaliação psicológica, sendo os testes psicológicos as ferramentas quase que fundamentais para realizar tal atividade de modo que as qualidades psicométricas desses testes começavam a ser discutidas e/ou questionadas. É nesse contexto histórico da prática que surge o Código de Trânsito Brasileiro de 1997.

\section{Do CTB de 1997 às conquistas cada vez mais consolidadas}

Em 23 de setembro de 1997 foi promulgada pelo Congresso Nacional a Lei $\mathrm{n}^{\circ}$ 9.503, que instituiu o Código de Trânsito Brasileiro, substituindo o Código Nacional de Trânsito. A lei foi sancionada pela Presidência da República e entrou em vigor em 22 de janeiro de 1998. O novo código estabelece, em seu artigo primeiro, que o 'trânsito seguro é um direito de todos e um dever dos órgãos e entidades do Sistema Nacional de Trânsito" (Lei no 9.503, 1998), que se tornaria a maior de suas diretrizes. Importante ressaltar que o CTB foi sancionado com o veto presidencial para a obrigatoriedade do exame psicológico aos candidatos à habilitação e aos condutores. A mobilização da categoria, assim como ocorreu nos anos de 2019 a 2021, fez com que o veto presidencial fosse derrubado antes da vigência da Lei. Uma das questões positivas resultantes do veto, além de mostrar a união da categoria, foi servir como base para a efetiva regulamentação dos aspectos que deveriam ser avaliados nos exames psicotécnicos, algo que era sinalizado como uma das grandes carências da área desde a década de 1950.

A esse respeito, a primeira normativa publicada pelo Contran (1998a) que versa sobre os aspectos psicológicos a serem avaliados é a Resolução no 51/98 que, menos de seis meses após sua publicação, foi alterada pela Resolução no 80/98 (1998b). Importante destacar que as maiores conquistas destas resoluções foram a definição das áreas a serem avaliadas: a) percepto-reacional, motora e nível mental; b) área do equilíbrio psíquico; e c) habilidades específicas. A função desempenhada agora passa a ser denominada "avaliação psicológica pericial" e não mais "exame psicotécnico" e, por fim, houve a inclusão da necessidade de realização de um curso de psicólogo perito examinador do trân- sito, com duração de 120 horas/aula, com o objetivo de atualizar os profissionais da área.

Acompanhando os avanços relatados, tem-se também o importante papel do Conselho Federal de Psicologia que, com o objetivo de regulamentar juntamente às determinações do Contran, publicou, em 2000, a Resolução CFP no 12/2000, que instituiu o manual para avaliação psicológica de candidatos à Carteira Nacional de Habilitação e condutores de veículos automotores. Com isso, o CFP começou a acompanhar as normativas do Contran, dando mais respaldo aos profissionais que atuam na área. Importante destacar que, a partir dessa resolução, o CFP iniciou um processo contínuo de acompanhamento e participação nas instâncias consultivas e deliberativas do sistema nacional de trânsito.

Outro marco importante para a psicologia, e que impactou fortemente a psicologia do trânsito, foi a consolidação das resoluções relativas ao Título Profissional de Especialista, por meio da publicação da Resolução $n^{\circ} 14 / 2000$ que instituiu as primeiras especialidades reconhecidas pelo CFP, entre as quais, a especialidade em Psicologia de Trânsito. Hoje, com a inclusão em 2019 da especialidade em Avaliação Psicológica, existem 13 especialidades em psicologia constantes na Resolução CFP no 013/2007 atualmente em vigor.

$\mathrm{Na}$ esteira dos questionamentos e ações judiciais que vinham ocorrendo devido às avaliações psicológicas realizadas sem os cuidados científicos necessários, sem os instrumentos adequados e, consequentemente, sem resultados válidos, foi publicada a Resolução CFP no 025/2001. A normativa definiu o teste psicológico como método de avaliação privativo do psicólogo, regulamentando sua elaboração, comercialização e uso. O CFP lançou, assim, as bases do que viria a ser o Sistema de Avaliação de Testes Psicológi$\cos$ (SATEPSI) (Resolução CFP no 002, 2003), além dos pontos que seriam questionados posteriormente pela Ação Direta de Inconstitucionalidade (ADI) 3481.

Como pode ser observado, os 10 anos subsequentes ao СТВ foram, de fato, de conquistas extremamente relevantes que, por vezes, passaram despercebidas pela categoria. Assim, não é ousado falar que a área de trânsito é, talvez, uma das que mais avançou ao longo da história da psicologia no Brasil, mesmo que com críticas e problemas a serem resolvidos.

Exemplo desse avanço também pode ser observado nas resoluções subsequentes que foram publicadas tanto pelo Contran quanto pelo CFP. No que 
diz respeito ao Contran, em 2008 o órgão publicou as Resoluções no 267 e no 283, que versavam, dentre outros aspectos, sobre os processos psíquicos que deveriam ser avaliados e sobre a qualificação e atualização dos profissionais da área. Sobre esses pontos, é importante mencionar que os processos psíquicos a serem avaliados foram atualizados no sentido de aprofundar as questões cognitivas, emocionais e de personalidade a serem aferidas. Por sua vez, a qualificação e a atualização se deram a partir da exigência de que o curso de perito examinador aumentasse para 180h, de modo que, a partir de 2013, os psicólogos só seriam credenciados aos departamentos estaduais de trânsito (Detrans) se fossem portadores de título de Especialista em Psicologia de Trânsito reconhecido pelo CFP. Em relação ao CFP, o conselho continuou acompanhando as regulamentações do Contran e orientando a categoria. Assim, em 2009 publicou a Resolução no 007/2009, revogando a no 012/2000 e instituindo novas normas e procedimentos para a avaliação psicológica no contexto do trânsito.

Em que pesem as regulamentações de 2008 e 2009 do Contran e CFP terem sido um avanço para a área, é preciso dizer que a necessidade de possuir Título de Especialista em Psicologia de Trânsito para se credenciar aos Detrans foi bastante questionada e combatida. Inclusive, em 2012, há menos de um ano do prazo para a especialidade, o Contran ainda recebia questionamentos sobre a resolução, ocasionando a judicialização da exigência. Muitos Detrans publicavam portarias informando que o credenciamento seria realizado apenas com o curso de perito, enquanto psicólogos falavam em "direito adquirido", dentre outros aspectos.

Isso contribuiu, também, para que em 2012 o Contran publicasse a Resolução no $425 / 12$, vigente até o momento, que versa, dentre outros aspectos, sobre os critérios relativos à avaliação psicológica. Nela, a exigência do título de especialista foi prorrogada para 2015, considerando os fatos e as dificuldades já mencionadas, inclusive os escassos cursos de pós-graduação em Psicologia do Trânsito pelo país. Muito relevante destacar que já em 2008, e mais ainda em 2012, as resoluções foram escritas com a participação de representantes da psicologia, incluindo a representação do Conselho Federal de Psicologia na Câmara Temática de Saúde e Meio Ambiente (CTSMA).

Todos esses aspectos mencionados e as movimentações de diferentes grupos e associações de trânsito dispersos pelo Brasil foram criando as condições para que, mais uma vez, a Psicologia do Trânsito ganhasse força e representatividade. Foi nesse período que a Associação Brasileira de Psicologia de Tráfego (ABRAPSIT), entidade científica sem fins lucrativos, foi fundada, em 2015. A ABRAPSIT tem como objetivos principais o desenvolvimento técnico, ético e científico da área, assim como a atuação junto ao poder público para que a gestão de tráfego receba o tratamento de atividade de saúde pública. Assim, desde sua fundação, a associação atua na esfera legislativa - na Câmara dos Deputados e no Senado Federal -, na esfera executiva governos estaduais e federais - e na esfera administrativa, como no Denatran e no Contran, em defesa da importância da Psicologia do Trânsito não apenas para a primeira habilitação e para a atividade remunerada, mas em todos os processos de renovação, nas intervenções com os infratores contumazes e em atuações multidisciplinares no sistema nacional de trânsito.

Como pode ser evidenciado, o período retratado neste tópico contempla uma série de conquistas e avanços para a área da Psicologia do Trânsito e, mais especificamente, para o contexto da avaliação psicológica pericial para fins de $\mathrm{CNH}$. A ideia dessas seções foi oferecer um breve panorama histórico. No tópico seguinte, o objetivo é discutir questões que desde 2018 têm impactado a área e pensar possibilidades para os desafios presentes e futuros.

\section{De 2018 a 2021: Marcos históricos}

É indubitável que os últimos anos têm sido muito positivos para a Psicologia do Trânsito no Brasil e, ao nosso ver, o futuro também nos parece promissor para a área. Mas quais os fatos que nos fazem acreditar nisso? Em primeiro lugar, em 2018 consolidou-se uma parceria entre o CFP e a ABRAPSIT que possibilitou que a área ganhasse força em diferentes esferas. A título de exemplo, podem-se citar duas ações que demonstram as conquistas alcançadas em grande parte como fruto dessa parceria. São elas: a publicação da Resolução CFP no 01/2019 e as mobilizações junto a parlamentares da Câmara dos Deputados e do Senado Federal em defesa da perícia psicológica contínua contra as alterações propostas pelo PL no 3267/2019 e em favor da especialidade em Psicologia de Trânsito.

Sobre a primeira ação, é importante destacar que, historicamente, o Contran publicou resoluções e normativas (como as no 51/80, no 80/1998, no 267/2008, $n^{\circ} 425 / 2012$ ) nas quais o CFP participou como cola- 
borador na construção, dividindo espaços com outras representações que, muitas vezes, não eram da área da psicologia, uma vez que as Câmaras Temáticas do Contran nas quais as propostas de resolução são elaboradas são compostas por representantes de entidades científicas, de classe e da sociedade civil. Dessa forma, após as normativas do Contran, o CFP precisou se adequar a elas (Resolução CFP no 12, 2000; Resolução CFP no 07, 2009). A parceria entre CFP e ABRAPSIT, assim como a ativa participação que a ABRAPSIT começou a exercer na Câmara Temática de Saúde e Meio Ambiente (CTSMA), fez que, em 2018, o Contran estabelecesse um diálogo mais direto com as entidades com a finalidade de elaboração de uma normativa única que não apresentasse diferenças para a prática profissional na área da psicologia do trânsito.

Para isso, um grupo de trabalho integrado pela ABRAPSIT, por representantes do CFP na CTSMA do Contran, por um membro da Comissão Consultiva em Avaliação Psicológica do CFP, por um membro do Detran-RS, por um membro do Detran-PE e por um membro representante da sociedade civil foi formado. A proposta de alteração da resolução foi amplamente discutida nesse grupo de trabalho e aprovada por unanimidade - com a aprovação dos 50 delegados que representavam cada um dos 23 CRP e o CFP na Assembleia de Políticas, Administração e Finanças (APAF) do Conselho Federal de Psicologia em dezembro de 2018.

Assim, em fevereiro de 2019 foi publicada a Resolução CFP no 01/2019, que substituiu a de no 007/2009 e trouxe como principais mudanças a alteração do termo avaliação psicológica por perícia psicológica, com o entendimento de que a perícia no trânsito é uma avaliação psicológica compulsória, portanto, de caráter obrigatório, e que o candidato à habilitação ou condutor a realiza em cumprimento às exigências legais e normativas especificas. Outras modificações relevantes para a área estão relacionadas ao processo pericial em si, em especial as quatro a seguir que foram, ao nosso ver, as mais relevantes: a) a explicitação de que a entrevista psicológica tem carácter individual e obrigatório; b) a definição de forma objetiva das habilidades mínimas necessárias, divididas em aspectos cognitivos, juízo critico/comportamento e traços de personalidade, c) a explicitação de que o psicólogo tem a prerrogativa de decidir quais são os testes psicológicos empregados na perícia psicológica, desde que com parecer favorável do SATEPSI; e d) o reconhecimento de que o documento resultante da perícia psicológica será o atestado psicológico, seguindo as orientações da Resolução CFP no 06/2019 que alinhou a especificidade das áreas de atuações. Pode-se dizer que todas essas alterações deram ao psicólogo responsável pela perícia psicológica uma maior autonomia na tomada de decisões e, ao mesmo tempo, padronizou minimamente o trabalho, aspecto este que era uma demanda desde as décadas iniciais em que a prática surgiu. Por fim, é importante destacar que, ao elaborar a resolução, contou-se com a garantia de que a Resolução do Contran que viesse a substituir a no $425 / 12$ apresentaria a mesma redação. Em meio às mudanças políticas e administrativas, a estrutura e composição das Câmaras Temáticas, do próprio Contran e do Denatran foram alteradas. O CFP e a ABRAPSIT permaneceram representados na nova composição, agora chamada de Câmara Temática de Educação e Saúde (CTES), mesmo que apenas com dois representantes em lugar dos quatro anteriores.

A partir da eleição presidencial de 2018, que levou Jair Bolsonaro à presidência do Brasil, ocorreram uma série de mudanças e alterações no cenário político e social brasileiro. No caso específico do trânsito, em 2019 o presidente apresentou em mãos ao parlamento o Projeto de Lei no 3267, no qual propunha uma série de alterações ao Código de Trânsito. Entre as proposições apresentadas, pode-se destacar as de impacto direto na psicologia, como: a ampliação dos prazos de validade da $\mathrm{CNH}$ (passando para 10 anos até os 65 anos e 5 anos após esta idade); a retirada da competência dos Detrans para realização e, consequentemente, credenciamento dos exames médicos e psicológicos; a alteração das avaliações psicológicas já realizadas com a extensão automática dos prazos concedidos; alteração na composição e competências do Contran, órgão em que as normas sobre as perícias psicológicas são aprovadas, entre outros pontos que afetavam diretamente a segurança no trânsito, como a retirada da obrigatoriedade da cadeirinha para $o$ transporte infantil.

Neste cenário difícil, nova mobilização surgiu, capitaneada pelo CFP, pela ABRAPSIT e pelo Fórum de Entidades Nacionais da Psicologia Brasileira (FENPB). A categoria se uniu para defender a contribuição histórica da Psicologia do Trânsito na prevenção de acidentes e promoção da saúde. Por meio dessa união, houve um intenso movimento nas redes sociais, assim como diálogos digitais, notas técnicas, audiências 
públicas, além de uma série de reuniões no Ministério da Infraestrutura, no Denatran, no Contran, na Casa Civil, na presidência da Câmara e do Senado Federal, com todos os líderes e vice-líderes partidários, com os presidentes de partidos, com os parlamentares integrantes da Comissão Especial criada para analisar o PL e com os representantes federais por meio de reuniões em seus estados ou em Brasília. Houve, enfim, uma articulação nacional da categoria.

O projeto de lei sofreu inúmeras alterações durante todo este processo de elaboração na Câmara dos Deputados que findaram por diminuir os prejuízos presentes na proposta inicial e trazer ainda novas conquistas para a psicologia. A validade da $\mathrm{CNH}$ permaneceu em 10 anos, mas, para condutores até 50 anos, ela foi escalonada para 5 anos de validade até os 70 anos de idade e 3 anos para aqueles a partir dos 70 anos e os Detrans permaneceram responsáveis pela realização e delegação dos exames médicos e psicológicos. A especialidade em psicologia do trânsito reconhecida pelo CFP passou a ser obrigatória para a realização dos exames para as carteiras nacionais de habilitação. Os prazos de validade das $\mathrm{CNH}$ submetem-se a expertise técnico pericial do especialista perito examinador. As validades dos exames periciais constantes nos documentos expedidos anteriormente permanecem de acordo com seu resultado pericial e os condutores infratores passaram a ter que se submeter a avaliação psicológica "quando se envolverem em acidente grave para o qual tenham contribuído, quando condenado judicialmente por delito de trânsito e, a qualquer tempo, se for constatado que o condutor está colocando em risco a segurança do trânsito" (Lei $n^{\circ} 14.071,2020$ ). Os profissionais peritos da saúde que atuam na área passaram a ter um prazo de 3 anos para realizarem sua especialização para área de atuação e os profissionais especialistas deverão ser regularmente fiscalizados pelos conselhos profissionais juntamente com os órgãos executivos de trânsito dos estados e do Distrito Federal.

Não pode deixar de ser mencionado que isso ocorreu em meio ao surto ocorrido em função da doença causada pela nova espécie do coronavírus, a SARS-CoV-2, conhecida como Covid-19' ${ }^{1}$ que fez com que a Organização Mundial da Saúde (OMS) declarasse, em 11 de março de 2020, uma pandemia global (OMS, 2020). Como destacam Cristo, Soares Jr.,
Luiz e Nascimento (2020), a pandemia teve grandes impactos na mobilidade, na acessibilidade e no trabalho do psicólogo do trânsito.

No que tange ao trabalho psicológico, e mais especificamente no que se refere à perícia psicológica, sua realização precisou ser suspensa por um período que variou de um a cinco meses, dependendo da unidade da federação. Ainda, as próprias características da perícia não permitiram que o formato híbrido ou remoto fosse adotado. Esse aspecto teve grande impacto no fazer profissional e fez com que uma série de questões começassem a ser repensadas. A esse respeito, e considerando que, como já relatado, o trabalho pericial do psicólogo no contexto do trânsito sempre teve os testes psicológicos como uma de suas ferramentas principais, se fez premente que tais instrumentais possuam caraterísticas que permitam sua utilização de forma remota. Aqui precisa ser destacado o esforço evidenciado tanto por parte do CFP, ao normatizar por meio de notas técnicas o uso remoto de testes, quanto pelos autores e editoras de testes, que rapidamente iniciaram um processo de estudos de adaptação de testes em formato lápis e papel ou on-line para o formato de aplicação remota.

No entanto, é importante refletir que, no caso das perícias psicológicas durante o processo de $\mathrm{CNH}$, os testes psicológicos que permitam uma aplicação em formato remoto podem contribuir para pensar uma nova forma para a prática profissional. No entanto, como destacam Cristo et al. (2020), no caso da perícia psicológica o contato presencial parece ser ainda algo fundamental. Ainda pode-se citar o destaque de Muniz, Cardoso, Rueda e Noronha (2021), ao mencionar que, se por um lado o atendimento de forma remota vai ao encontro de uma demanda urgente da sociedade, ele ainda carece de estudos que possibilitem conhecer possíveis impactos dessa nova modalidade, tanto em aspectos técnicos quanto éticos. Assim como é necessário que tal modalidade leve em consideração a realidade social, histórica e cultural da população brasileira que, em sua maioria, ainda carece de acesso à tecnologia da informação.

Como pode ser visto, os últimos três anos trouxeram uma série de mudanças na perícia psicológica no trânsito. Se por um lado a área cresceu, se desenvolveu e teve conquistas importantes, a pandemia de Covid-19 nos colocou diante da necessidade de pen-

${ }^{1}$ No momento da submissão deste artigo, 25 de maio de 2021, tinha se superado a assustadora marca de 450.000 óbitos no Brasil. 
sar novas formas para nosso fazer profissional que, certamente, deverão permanecer por bastante tempo. Aliado a isso, tem-se talvez os dois fatos mais importantes do período: a Ação Direta de Inconstitucionalidade $n^{\circ} 3481$ e a promulgação da Lei no ${ }^{\circ}$ 14.071/2020.

\section{ADI no 3481 e Lei no 14.07 1/2020: dois acontecimentos de impacto na área}

Para além da trágica pandemia pela qual o Brasil e o mundo estão passando há mais de um ano, 2021 ficará marcado como o ano em que mudanças drásticas ocorreram na psicologia brasileira, impactando diretamente em quase todo o fazer profissional e, principalmente, na perícia psicológica no contexto do trânsito. No dia 5 de março de 2021 ocorreu o julgamento virtual da ADI 3481 do Supremo Tribunal Federal (STF) que declarou inconstitucionais dispositivos que restringiam a comercialização e o uso de manuais de testes psicológicos a profissionais inscritos no conselho, constantes na Resolução CFP no 02/2003. Na decisão do relator, ministro Alexandre de Moraes, por um lado foi reconhecida a competência legal do CFP para regulamentar e aprovar testes psicológicos como forma de conferir confiabilidade à sua utilização, por outro, reconheceu-se que a utilização de testes psicológicos é função privativa do psicólogo. De acordo com o ministro, isso não justificaria a restrição à comercialização dos testes psicológicos, uma vez que eles foram equiparados a livros ou publicações voltadas para o conhecimento científico (Zanini, Reppold, Muniz, Noronha, \& Rueda, 2021). Diante disso, a pergunta que grande parte da categoria se faz é: quais os impactos dessa decisão para a perícia psicológica no trânsito e quais são as alternativas?

Sobre isso, Zanini et al. (2021) problematizaram a ausência de regulamentação no uso e comercialização de testes psicológicos sob a ótica da teoria da ponderação de princípios do jurista alemão Robert Alexy, fundada a partir dos argumentos de "adequação", "necessidade" e "razoabilidade" das normas. Os autores concluíram que a restrição ao uso e comercialização dos testes psicológicos é adequada, é necessária e é razoável. Alguns dos argumentos apresentados pelos autores se referem ao fato de ser o psicólogo o único profissional que tem a junção dos conhecimentos teóricos e das condições técnicas para construir e utilizar testes psicológicos. Sem essa restrição, os testes poderão ser utilizados indevidamente para fins distintos daqueles preconizados, assim como poderão ser ensinados sem qualquer controle, dentre outros aspectos.
Pensando no contexto da perícia psicológica no trânsito, é necessário destacar que os benefícios sociais da avaliação psicológica são reconhecidos pela população. Um estudo realizado por Lamounier e Rueda (2005) mostrou que os candidatos à obtenção da CNH consideraram que a avaliação psicológica é importante, que o processo auxilia à identificação de fatores de risco para diminuir o índice de acidentes e, por fim, julgaram ser positivo que a avaliação psicológica fosse realizada com maior periodicidade. Isso, aliado ao fato evidenciado por Reppold, Wechsler, Almeida, Elosua e Hutz (2020), de que mais de $90 \%$ dos psicólogos brasileiros afirmam que utilizam testes psicológicos em seu fazer profissional, demonstra a importância e necessidade de regulamentar essa temática.

Se pensarmos em situações que podem ocorrer no contexto do trânsito, como ficaria e como pode ser controlado o ensino e/ou treinamento de testes psicológicos para pessoas que passarão pela perícia? Se qualquer profissional poderá comprar os testes, como fica a possibilidade de um candidato ser treinado a responder os testes psicológicos antes do processo pericial? Caso o resultado do atestado psicológico seja favorável, será que de fato foram avaliadas as características necessárias nessa pessoa? Destaca-se que, há décadas, o CFP e as demais entidades da área da avaliação psicológica atuam para proteger os instrumentos psicológicos amplamente divulgados na internet. No entanto, essas dificuldades ultrapassam as fronteiras do Brasil, pois muitos dos sites e plataformas estão hospedados em outros países, o que dificulta a interferência direta de nossas legislações ou solicitações. As excessivas judicializações das avaliações psicológicas, particularmente as compulsórias, também colocou em evidência o debate sobre o acesso aos instrumentos e o treinamento para uma avaliação "satisfatória".

Diante dos argumentos apresentados, é necessário afirmar, mais uma vez, que a liberação generalizada dos testes de forma imediata impactará diretamente na qualidade e nas condições existentes para a realização da perícia psicológica técnica e eficaz na prevenção de acidentes.

Após mais de um ano e meio de intensos diálogos na Câmara dos Deputados e no Congresso Nacional, em 13 de outubro de 2020, foi sancionada a Lei no 14.071 que altera o Código de Trânsito Brasileiro. A sanção trouxe impactos diretos ao contexto da saúde no trânsito, com o veto presidencial à exigência da especialidade em psicologia do trânsito e em medi- 
cina de tráfego para a realização dos respectivos exames, à avaliação dos condutores infratores contumazes e ao prazo para os profissionais atuantes na área se adequarem à obrigatoriedade da especialidade.

Ante a ameaça de novo impacto significativo não apenas na atuação da psicologia do trânsito, mas também, na preservação da vida, fez-se necessário a intensificação da articulação junto aos parlamentares. A defesa da saúde no trânsito se fez novamente presente na parceria do CFP e ABRAPSIT, juntamente com as entidades médicas representativas como o Conselho Federal de Medicina (CFM), a Associação Brasileira de Medicina de Tráfego (ABRAMET) e a Associação Médica Brasileira (AMB). Foram novos meses de lutas, com defesas técnicas, científicas e atuações políticas para demonstrar a importância da promoção da saúde no contexto do tráfego viário. Em 17 de março de 2021, apenas um mês antes de entrarem em vigência as alterações do CTB, as conquistas da categoria vieram com a derrubada dos vetos presidenciais pelo Congresso Nacional com uma maioria inquestionável.

Foram dois anos de presenças semanais constantes no parlamento brasileiro e em processo de elaboração de documentos técnicos e de comparecimento a reuniões e audiências que tiveram como resultado o primeiro reconhecimento legal de uma especialidade da psicologia para sua atuação profissional. Isso evidencia o reconhecimento da nossa ciência, a importância de uma formação continuada e ética e o valor da união e representatividade da categoria através do CFP e das entidades científicas da área de atuação.

\section{À guisa de conclusão}

Os desafios da psicologia do trânsito, como todo campo científico em evolução, ainda são numerosos. Contudo, algumas perspectivas se apresentam e precisam ser refletidas a partir dos eventos ocorridos. É preciso, fundamentalmente, entender a perícia psicológica no trânsito como uma avaliação psicológica compulsória em um processo técnico-científico que visa constatar, junto aos condutores ou candidatos à habilitação, seus construtos psicológicos, suas habilidades, sua personalidade, seu comportamento, suas atitudes e suas condições emocionais e psicológicas inerentes à condução segura, por meio de métodos, técnicas e instrumentos devidamente reconhecidos pela Psicologia (CFP, 2019a). Portanto, os testes psicológicos são uma parte do processo pericial e fornecem informações à tomada de decisão do avaliador para a demanda específica.
Como ressaltam Villemor-Amaral e Resende (2018), os instrumentos psicológicos podem favorecer uma maior empatia ao profissional e auxiliar na identificação das histórias pessoais, das defesas e estratégias de enfrentamento e dos recursos e das dificuldades de mudanças. A perícia, nesta perspectiva, exige empatia, sensibilidade e uma maior propriedade no manejo de técnicas de exames, assim como a capacidade de intervenção do avaliador para ampliar a compreensão dos fenômenos dentro do contexto avaliado e da singularidade do avaliando.

É fundamental ainda refletir sobre o panorama do trânsito, no qual se observam os comportamentos rotineiros e habituais no ato de conduzir. Cristo (2019) traz a importância de medidas psicológicas de autorrelato como auxílio ao diagnóstico de comportamentos habituais, especialmente os que apresentam riscos na direção veicular e como subsídio para as intervenções nestes comportamentos. Essas intervenções agem sobre os comportamentos de risco que podem comprometer a segurança viária e ocasionar sinistros de trânsito, afetados pelas características de personalidade e pelas atitudes de segurança de forma distinta em fases específicas da vida e de acordo com a experiencia do condutor. (Lucidi et al. 2019; Martinussen, Møller \& Grato, 2014; Ulleberg \& Rundmo, 2003).

A utilização das Tecnologias de Informação e Comunicação (TICs) aplicadas à perícia psicológica também é uma possibilidade atual e que traz muitas perspectivas futuras. Mesmo com a Resolução CFP n ${ }^{\circ}$ 11/2018 que regulamenta a prestação de serviços psicológicos realizados por meio das TIC, ainda é preciso evoluir significativamente neste campo. No Brasil, a falta de acesso à internet, de equipamentos próprios para isso, assim como do domínio da tecnologia, são fatores limitantes na utilização das TICs para o trânsito, considerando a diversidade social, cultural, econômica e educacional dos condutores. É preciso, então, o desenvolvimento de técnicas informatizadas, remotas, mediadas, que possam ser validadas e analisadas para esse contexto específico. Assim, nas avaliações psicológicas compulsórias faz-se mister entender que o processo de mudança necessita ser gradual, possibilitando o acesso em todas as localidades e condições do país, sem prejuízos ao cidadão.

Os testes psicológicos também precisam adequar-se ao novo cenário provocado pelas alterações legais. Além disso, pensar na adoção de recursos computacionais, testes informatizados, testes adaptativos, manu- 
ais sem crivos e de folhas de respostas ou de correção, entre tantas outras possibilidades tecnológicas que surgem e evoluem a cada dia. Ao mesmo tempo em que desenvolvemos novas possibilidades técnicas e científicas, não se pode, contudo, esquecer as esferas administrativas, jurídicas e legislativas. Como foi observado ao longo da construção histórica para a especialidade em psicologia do trânsito, é fundamental participar da elaboração de normas e políticas públicas que defendam a ciência e a profissão. O diálogo da psicologia com a sociedade precisa se fazer presente em todas as suas esferas e, assim, oferecer garantias de uma atuação profissional especializada e reconhecida que possa contribuir com a saúde mental e a qualidade de vida de cada indivíduo, a missão maior de nossa ciência.

Reforçando, como preceitua a Resolução CFP $\mathrm{n}^{\circ}$ 09/2018, que a avaliação psicológica pode se utilizar de fontes fundamentais e complementares e que o profissional possui a prerrogativa para escolha dos métodos, técnicas e instrumentos a serem utilizados, desde que devidamente fundamentados na literatura científica psicológica, há uma gama significativa de possibilidades. O que permite que $\mathrm{a}(\mathrm{o})$ especialista em Psicologia de Trânsito possa estabelecer baterias diárias diversas e contextualizadas, dificultando o treino prévio do candidato.

Toda a categoria também precisa comprometer-se com a qualificação técnico-científica, no combate contra a divulgação indevida de dados e orientações, na preservação da ética profissional e na contribuição em estudos para o desenvolvimento da atuação profissional neste momento de construção de novos modelos. Muitos desafios e possibilidades estão no horizonte, enquanto caminha-se em direção ao futuro da perícia psicológica no trânsito, os preceitos éticos, técnicos, científicos e empíricos são as balizas a serem seguidas em uma avaliação psicológica dos condutores abrangente, contextualizada, dinâmica e sistemática.

\section{Referências}

Conselho Federal de Psicologia. (2000a). Resolução CFP no 12/2000. Institui o Manual para Avaliação Psicológica de candidatos à Carteira Nacional de Habilitação e condutores de veículos automotores. CFP.

Conselho Federal de Psicologia. (2000b). Resolução CFP no 14/2000. Institui o título profissional de Especialista em Psicologia e dispõe sobre normas e procedimentos para seu registro. CFP.

Conselho Federal de Psicologia. (2001). Resolução CFP no 025/2001. Define teste psicológico como método de avaliação privativo do psicólogo e regulamenta sua elaboração, comercialização e uso. CFP.

Conselho Federal de Psicologia. (2003). Resolução CFP no 002/2003. Define e regulamenta o uso, a elaboração e a comercialização de testes psicológicos e revoga a Resolução CFP no 025/2001. CFP.

Conselho Federal de Psicologia. (2007). Resolução CFP no 013/2007. Institui a Consolidação das Resoluções relativas ao Título Profissional de Especialista em Psicologia e dispõe sobre normas e procedimentos para seu registro. CFP.

Conselho Federal de Psicologia. (2009). Resolução CFP no 007/2009. Revoga a Resolução CFP no 012/2000, publicada no DOU do dia 22 de dezembro de 2000, Seção I, e institui normas e procedimentos para a avaliação psicológica no contexto do trânsito. CFP.

Conselho Federal de Psicologia. (2018a). Resolução CFP no 009/2018. Estabelece diretrizes para a realização de Avaliação Psicológica no exercício profissional da psicóloga e do psicólogo, regulamenta o Sistema de Avaliação de Testes Psicológicos - SATEPSI e revoga as Resoluções no 002/2003, no 006/2004 e no 005/2012 e Notas Técnicas $n^{\circ}$ 01/2017 e 02/2017. CFP.

Conselho Federal de Psicologia. (2018b). Resolução CFP no 011/2018. Regulamenta a prestação de serviços psicológicos realizados por meio de tecnologias da informação e da comunicação e revoga a Resolução CFP no 11/2012. CFP.

Conselho Federal de Psicologia. (2019a). Resolução CFP no 01/2019. Institui normas e procedimentos para a perícia psicológica no contexto do trânsito e revoga as Resoluções CFP no 007/2009 e 009/2011. CFP.

Conselho Federal de Psicologia. (2019b). Resolução CFP no 06/2019. Institui regras para a elaboração de documentos escritos produzidos pela(o) psicóloga(o) no exercício profissional e revoga a Resolução CFP no 15/1996, a Resolução CFP n $n^{\circ} 07 / 2003$ e a Resolução CFP no 04/2019. CFP.

Conselho Nacional de Trânsito. (1998a). Resolução no 51. Dispõe sobre os exames de aptidão física e mental e os exames de avaliação psicológica a que se refere o inciso I, do art. 147 do Código de Trânsito Brasileiro e os $\$ \$ 3^{\circ}$ e $4^{\circ}$ do art. $2^{\circ}$ da Lei 9.602/98. Contran. 
Conselho Nacional de Trânsito. (1998b). Resolução no 80. Altera os Anexos I e II da Resolução no 51/98-CONTRAN, que dispõe sobre os exames de aptidão fisica e mental e os exames de avaliação psicológica. Contran.

Conselho Nacional de Trânsito. (2008a). Resolução $n^{\circ}$ 267. Dispõe sobre o exame de aptidão física e mental, a avaliação psicológica e o credenciamento das entidades públicas e privadas de que tratam o art. 147 , I e $\$ \S 1^{\circ}$ a $4^{\circ} \mathrm{e}$ o art. 148 do Código de Trânsito Brasileiro. Contran.

Conselho Nacional de Trânsito. (2008b). Resolução no 283. Altera a Resolução no 267, de 15 de fevereiro de 2008, do CONTRAN, que dispõe sobre o exame de aptidão física e mental, a avaliação psicológica e o credenciamento das entidades públicas e privadas de que tratam o art. 147, I e $\$ \S 1^{\circ}$ e $4^{\circ}$ e $\mathrm{o}$ art. 148 do Código de Trânsito Brasileiro. Contran.

Conselho Nacional de Trânsito. (2012). Resolução no 425. Dispõe sobre o exame de aptidão física e mental, a avaliação psicológica e o credenciamento das entidades públicas e privadas de que tratam o art. 147, I e $\$ \$ 1^{\circ}$ a $4^{\circ}$ e o art. 148 do Código de Trânsito Brasileiro. Contran.

Cristo, F. (2019). Hábito e comportamento no trânsito: Medidas psicológicas e intervenções. In F. Cristo (Org.), Psicologia do Trânsito e Transporte: Manual do especialista (pp.171-198). Vetor.

Cristo, F., Soares Jr., R. C., Luiz, K. G., \& Nascimento, A. S. (2020). Impactos da Covid-19 na mobilidade, na acessibilidade e no trabalho do Psicólogo do Trânsito. Psicologia: Ciência e Profissão, 40, e242863, 1-13. https:// doi.org/10.1590/1982-3703003242863 .

Decreto-Lei no 2.994, de 28 de janeiro de 1941. (1941). Código Nacional de Trânsito. https:/ /www2.camara.leg.br/ legin/fed/declei/1940-1949/decreto-lei-2994-28-janeiro-1941-412976-publicacaooriginal-1-pe.html

Decreto-Lei no 3.651, de 25 de setembro de 1941. (1941). Dá nova redação ao Código Nacional de Trânsito. Recuperado em 20 de maio de 2021 de https://legis.senado.leg.br/norma/528738/publicacao/15709155

Decreto-Lei no 9.545, de 5 de agosto de 1946. (1946). Dispõe sobre a habilitação e exercício da atividade de condutor de veículos automotores. https:/ /www2.camara.leg.br/legin/fed/declei/1940-1949/decreto-lei-9545-5-agosto-1946-417705-publicacaooriginal-1-pe.html

Departamento Nacional de Trânsito. (2010). 100 anos de legislação de trânsito no Brasil. Ministério das Cidades.

Fundação Getúlio Vargas. (1952). Seleção psicotécnica de motoristas. Arquivos Brasileiros de Psicotécnica, 4(3), 129-130.

Lamounier, R., \& Rueda, F. J. M (2005). Avaliação psicológica no trânsito: Perspectiva dos motoristas. Psic, 6(1), 35-42.

Lei $n^{\circ}$ 10.350, de 21 de dezembro de 2001. (2001). Altera a Lei no 9.503, de 23 de setembro de 1997 - Código de Trânsito Brasileiro, de forma a obrigar a realização de exame psicológico periódico para os motoristas profissionais. http://www.planalto.gov.br/ccivil_03/Leis/LEIS_2001/L10350.htm

Lei $n^{o}$ 14.071, de 13 de outubro de 2020. (2020). Altera a Lei no 9.503, de 23 de setembro de 1997, para modificar a composição do Conselho Nacional de Trânsito e ampliar o prazo de validade das habilitações; e dá outras providências. https://www.in.gov.br/en/web/dou/-/lei-n-14.071-de-13-de-outubro-de-2020-282461197

Lei $n^{\circ}$ 4.119, de 27 de agosto de 1962. (1962). Dispõe sobre os cursos de formação em psicologia e regulamenta a profissão de psicólogo. http://www.planalto.gov.br/ccivil_03/leis/1950-1969/14119.htm

Lei no 5.108, de 21 de setembro de 1966. (1966). Institui o Código Nacional de Trânsito. https://legislacao.presidencia.gov.br/atos $/$ tipo $=$ LEI\&numero $=5108 \&$ ano $=1966 \&$ ato $=092 E T U U 9 E M Z R V T d 59$

Lei $n^{\circ}$ 5.766, de 20 de dezembro de 1971. (1971). Cria o Conselho Federal e os Conselhos Regionais de Psicologia e dá outras providências. http://www.planalto.gov.br/ccivil_03/leis/15766.htm

Lei no 9.503, de 23 de setembro de 1997. (1997). Institui o Código de Trânsito Brasileiro. http:/ /www.planalto.gov.br/ ccivil_03/leis/19503compilado.htm

Lucidi, F., Girelli, L., Chirico, A., Alivernini, F, Cozzolino, M., Violani, C., \& Mallia, L. (2019). Personality traits and attitudes toward traffic safety predict risky behavior across young, adult, and older drivers. Frontiers in Psychology, 10, 536. https://doi.org/10.3389/fpsyg.2019.00536

Martinussen, L. M., Møller, M., \& Grato, C. G. (2014). Assessing the relationship between the driver behavior questionnaire and the driver skill inventory: Revealing sub-groups of drivers. Transportation Research Part F: Traffic Psychology and Behaviour, 26, 82-91. https://doi.org/10.1016/j.trf.2014.06.008 
Psicologia: Ciência e Profissão 2021 v. 41nspe1, e252541,1-13.

Muniz, M., Cardoso, L. M., Rueda, F. J. M., \& Noronha, A. P. P. (2021). Desafios da Avaliação Psicológica para a prática diante da atuação profissional mediada pela tecnologia de informação. Psico-USF, 26(spe.), 1-11.

Organização Mundial de Saúde. (2020). Folha Informativa Covid-19. Organização Mundial de Saúde. https:/ /www. paho.org/bra/index.php?option=com_content\&view=article\&id=6101:Covid19 \&Itemid=875

Reppold, C. T., Wechsler, S. M., Almeida, L., Elosua, P., \& Hutz, C. S. (2020). Perfil dos psicólogos brasileiros que utilizam Testes Psicológicos: Áreas e instrumentos utilizados. Psicologia: Ciência e Profissão, 40, e201348. https://doi.org 10.1590/1982-3703003201348

Rueda, F J. M. (2011). Psicologia do trânsito ou avaliação psicológica no trânsito: Faz-se distinção no Brasil? In Conselho Federal de Psicologia (Org.), Ano da Avaliação Psicológica: Textos geradores (pp. 103-114). CFP.

Silva, F. H. V. C. (2012). A psicologia do trânsito e os 50 anos de profissão no Brasil [Número especial]. Psicologia: Ciência e Profissão, 32, 176-193. https://doi.org 10.1590/S1414-98932012000500013

Ulleberg, P., \& Rundmo, T. (2003). Personality, attitudes and risk perception as predictors of risky driving behaviour among young drivers. Safety Science, 41, 427-443. https://doi.org/10.1016/S0925-7535(01)00077-7

Vieira, M. V. M., Pereira, A. O., \& Carvalho, A. V. (1953). O exame psicotécnico de motoristas no Distrito Federal. Arquivos Brasileiros de Psicotécnica, 5(4), 41-50.

Villemor-Amaral, A. E., \& Resende, A. C. (2018). Novo modelo de avaliação psicológica no Brasil [Número especial]. Psicologia: Ciência e Profissão, 38, 122-132. https://doi.org 10.1590/1982-3703000208680

Zanini, D. S., Reppold, C. T., Muniz, M., Noronha, A. P. P., \& Rueda, F. J. M. (2021). Por que regulamentar o uso dos Testes Psicológicos? Avaliação Psicológica, 20(2), 1-9.

Fabián J. M. Rueda

Psicólogo. Mestre e doutor em Psicologia pelo Programa de Pós-Graduação Stricto Sensu em Psicologia da Universidade São Francisco. Bolsista Produtividade 1C do CNPq. Docente do Programa de Pós-Graduação Stricto Sensu em Psicologia do Centro Universitário de Brasília (UniCEUB), Brasília - DF. Brasil.

E-mail: marinfabian@yahoo.com.br

(1) https://orcid.org/0000-0001-5173-0802

Juliana de Barros Guimarães

Psicóloga. Especialista em Psicologia do Trânsito e em Avaliação Psicológica pelo Conselho Federal de Psicologia. Diretora Científica da Associação Brasileira de Psicologia de Tráfego (ABRAPSIT), membro da Câmara Temática de Educação e Saúde do Contran e Diretora da área médica e psicológica do Departamento Estadual de Trânsito de Pernambuco (Detran-PE), Recife - PE. Brasil.

E-mail: julianabguimaraes@yahoo.com.br

(1) https://orcid.org/0000-0001-7037-0486

Endereço para envio de correspondência:

Av. do Ipiranga, 100, ap. 304, Ponte Preta. CEP: 13.041-720. Campinas - SP. Brasil.

Recebido 25/05/2021

Aceito 25/05/2021

Received 05/25/2021

Approved 05/25/2021

Recibido 25/05/2021

Aceptado 25/05/2021 
Rueda, F. J. M., \& Guimarães, J. B. (2021). Impactos na Psicologia do Trânsito..

Como citar: Rueda, F. J. M. \& Guimarães, J. B. (2021). Psicologia do Trânsito: Conquistas históricas, ADI 3481 e perspectivas para a área. Psicologia: Ciência e Profissão, 41, 1-13. https://doi.org/10.1590/1982-3703003252541

How to cite: Rueda, F. J. M. \& Guimarães, J. B. (2021). Traffic Psychology: Historical achievements, ADI 3481, and prospects for the area. Psicologia: Ciência e Profissão, 41, 1-13. https://doi.org/10.1590/1982-3703003252541

Cómo citar: Rueda, F. J. M. \& Guimarães, J. B. (2021). Psicología del Tránsito: Conquistas históricas, la ADI 3481 y las perspectivas para el área. Psicologia: Ciência e Profissão, 41, 1-13. https://doi.org/10.1590/1982-3703003252541 